Original Research Article

\title{
Drug utilization study in diabetic patients seeking medical treatment in a north Indian rural medical college hospital
}

\author{
Shweta Sharma $^{1 *}$, S. C. Chopra ${ }^{1}$, D. K. Sharma ${ }^{2}$, Juhi Singla ${ }^{1}$, Vinod Kapoor ${ }^{1}$
}

${ }^{1}$ Department of Pharmacology,

${ }^{2}$ Department of Medicine, SGT

Medical College, Hospital and

Research Institute, SGT

University, Village Budhera,

Gurugram-122505, Haryana,

India

Received: 17 February 2018

Revised: 28 February 2018

Accepted: 28 March 2018

*Correspondence to:

Dr. Shweta Sharma,

Email: drshwetasharma26@

gmail.com

Copyright: (C) the author(s), publisher and licensee Medip Academy. This is an openaccess article distributed under the terms of the Creative Commons Attribution NonCommercial License, which permits unrestricted noncommercial use, distribution, and reproduction in any medium, provided the original work is properly cited.

\begin{abstract}
Background: Diabetes Mellitus is a chronic disease and its life-long management causes burden on lifestyle and financial condition of the patients. Drug utilization studies provide useful insights into the current prescribing practices.

Methods: To evaluate the drug utilization pattern of anti-diabetic drugs in diabetic patients. A prospective observational study was carried out in adult diabetic patients visiting the Wards and Outpatient Department of General Medicine of a tertiary care hospital. The demographic data and utilization of different classes of anti-diabetic agents as well as individual drugs were analyzed. Results: In 125 patients (Male-65, Female-60), a total of 379 drugs (average $3.032 \pm 2.05)$ were used per day, out of which $76(20.05 \%)$ were rational fixed dose combinations (FDCs) and $261(68.86 \%)$ were prescribed from National List of Essential Medicines (NLEM) 2015. The number of drugs prescribed to be ingested was $326(86.01 \%)$ and $63(16.62 \%)$ were injectables.

Conclusions: It was found that the prescription tendencies of the doctors were quite rational. More improvement can be done by sensitizing them to prescribe more drugs from NLEM. The limitations in the affordability of rural population should be taken care of while prescribing drugs for this chronic disease.
\end{abstract}

Keywords: Anti-diabetic drugs, Diabetes mellitus, Drug utilization, National list of essential medicines

\section{INTRODUCTION}

Drug utilization research was defined by WHO in 1977 as the marketing, distribution, prescription, and use of drugs in a society, with special emphasis on the resulting medical, social and economic consequences. ${ }^{1}$ The principal aim of this is to facilitate the rational use of drugs in populations, interventions to improve drug use; quality control cycle; continuous quality improvement. Diabetes mellitus is a group of metabolic diseases characterized by hyperglycaemia resulting from defects in insulin secretion, insulin action, or both. ${ }^{2}$

The chronic hyperglycemia of diabetes is associated with long-term damage, dysfunction and failure of various organs, especially the eyes, kidneys, nerves, heart and blood vessels. Diagnosis of Diabetes Mellitus has profound implications on the individual from a medical and a financial standpoint. Proper planning for the management of patients with diabetes mellitus requires consideration of the important costs that diabetes imposes on the health system. According to International Diabetes 
Federation, in the year 2013, 65.1 million adults in India suffered from diabetes. ${ }^{3}$ It has been predicted that the prevalence of diabetes in the adult population in India will be $6 \%$ by the year $2025 .^{4}$

Modern principles of management of diabetes focus on disease prevention, screening high risk individuals and aggressive treatment of individuals in the pre-diabetic state. A long, asymptomatic phase in type 2 diabetes (up to a decade) is likely to be responsible for the observation that up to $50 \%$ of individuals with diabetes may have a diabetes-related complication at the time of diagnosis.

The current pharmacotherapy of diabetes mellitus includes treatment with drugs such as anti-diabetics and insulin. Oral agents are heterogeneous in their modes of action, safety profiles and tolerability. The main classes include agents that stimulate insulin secretion (sulfonylureas and rapid acting secretagogues), reduce hepatic glucose production (biguanides), delay digestion and absorption of intestinal carbohydrate ( $\alpha$-glucosidase inhibitors), improve insulin action (thiazolidinediones), incretin-based therapies like dipeptidyl peptidase-4 inhibitors and glucose reabsorption in PCT by SGLT-2 inhibitors. ${ }^{5-7}$

The consumption of oral anti-hyperglycaemic agents apart from insulin, injection equipment and self monitoring equipment indicates prescription tendencies and shows the influence on costs and provides indirect information about the quality of healthcare for patients with diabetes mellitus. ${ }^{8}$ Drug utilization studies provide useful insights into the current prescribing practices and also identify irrational prescribing. The consequences of irrational prescribing include non-adherence to medications, which can result in complications due to uncontrolled blood glucose levels and also escalate drug costs and health care costs.

Many drug utilization studies have been conducted in the past to study various changes in prescription patterns which might be due to introduction of new drugs and techniques. They might also vary in various areas like urban, suburban or rural depending upon the financial conditions of the population. This is a continuous process to improve the prescribing trends. In view of this, the present study was designed to evaluate the prescribing pattern of anti-diabetic drugs among diabetic patients in a rural tertiary care teaching hospital. This will be the baseline data for future reference as no drug utilization study has been performed earlier here.

\section{METHODS}

The present project was designed to obtain prescribing pattern of anti-diabetic and other drugs used in patients of type 1 and type 2-Diabetes Mellitus with regard to number of drugs used per patient per day, percentage of drugs used according to route of administration (oral/injectable/topical), percentage of drugs prescribed as
Fixed Dose Combinations (FDC) and percentage of drugs used as per Essential Drug List. ${ }^{9}$

Outpatient prescriptions and indoor case records prescribed for patients of Diabetes Mellitus were collected prospectively for one calendar year and recorded in specially designed performa. This was a cross sectional, observational study and was approved by Institutional Ethics Committee. No intervention was carried out. Written Informed Consent of all patients were recorded.

\section{Inclusion criteria}

Patients having type-1 or type-2 Diabetes Mellitus of age greater than or equal to 18 years of either gender were included. Diagnosis was made by physician of Department of Medicine.

\section{Exclusion criteria}

Diabetes secondary to causes like Acromegaly, Cushing's syndrome, Glucagonoma, Pheochromocytoma, Hyperthyroidism, Aldosteronism, Congenital syndromes like Down's syndrome, Klinefelter's syndrome, Turner's syndrome was excluded on clinical grounds. ${ }^{10}$

\section{History}

An interview regarding detailed general and drug history was taken from all the patients. Physical assessment of all the patients was done with respect to their height and weight based on which BMI was calculated. The details of all anti-diabetic drugs as well as all related and unrelated drugs were recorded with their composition, dosage, duration and route of administration.

\section{Statistical methods}

Data was collected on separate performa for each patient and was summarized and tabulated in MS Excel 2016 version using descriptive statistical techniques.

\section{RESULTS}

Out of 125 study subjects included, $65(52 \%)$ were male and $60(48 \%)$ were female. Amongst these, three patients $(2.4 \%)$ had type 1 diabetes mellitus and $122(97.6 \%)$ had type 2 diabetes mellitus.

In table 1 , total number of drugs used per day in all the patients were 379 with the average of $3.032 \pm 2.05$ (Mean \pm SD). Number of rational FDCs given to the patients was 76 , i.e., $20.05 \%$ of the total drugs prescribed whereas rational and irrational combined were 87 in count $(22.95 \%)$. Out of total of antidiabetic drugs prescribed, maximum was FDC of Metformin + Glimepiride, i.e., 50 (29.76\%). The sum of drugs prescribed from NLEM 2015 comes out to be 261 which is $68.86 \%$ of total drugs prescribed. The number of drugs prescribed to be ingested from oral route of administration was 326 , i.e., $86.01 \%$ of 
total number of drugs whereas the drugs given by injectable route of administration were 63 (16.62\%).

Average age of the included patients suffering from diabetes was $53 \pm 12.5$ years. Out of 125 patients, those living in rural area were 96, i.e., $76.8 \%$, in suburban area were 18 , i.e., $14.4 \%$ and in urban area were 11 , i.e., $8.8 \%$.

According to body mass index, 85 patients $(68 \%)$ had normal BMI in between $18.5-24.9 \mathrm{~kg} / \mathrm{m}^{2}$. A count of 28 patients $(22.4 \%)$ were overweight with BMI in range of $25.0-29.9 \mathrm{~kg} / \mathrm{m}^{2}$ whereas 7 patients $(5.6 \%)$ were obese, i.e., in between the range of $30.0-39.9 \mathrm{~kg} / \mathrm{m}^{2}$ and 5 patients (4\%) were underweight, i.e., having BMI less than $18.5 \mathrm{~kg} / \mathrm{m}^{2}$.

Table 1: Drug-use pattern of prescribed drugs.

\begin{tabular}{|ll|}
\hline Description & Result \\
\hline Number of drugs prescribed & 379 \\
\hline Mean number of drugs prescribed & $3.03 \pm 2.05^{*}$ \\
\hline Fixed Dose Combinations prescribed & $76(20.05 \%)$ \\
\hline Drugs prescribed from NLEM 2015 & $\begin{array}{l}261 \\
(68.86 \%)\end{array}$ \\
\hline Drugs to be administered by oral route & $\begin{array}{l}326 \\
(86.01 \%)\end{array}$ \\
\hline Drugs to be administered as injectables & $63(16.62 \%)$ \\
\hline
\end{tabular}

* Mean \pm Standard Deviation (SD), Figures in parenthesis ' () ' indicate percentage

The mode of initial diagnosis of the patients was also recorded (Table 2). A count of 37 patients (29.6\%) got it diagnosed by routine check-up, 27 patients $(21.6 \%)$ got it investigated on suspicion.

A number of 26 patients $(28.8 \%)$ got it diagnosed by chance and with complaint of polyuria and polyphagia each. Nine patients $(7.2 \%)$ came to know when they interacted complications.

Table 2: Distribution according to history of initial diagnosis.

\begin{tabular}{|lllll|}
\hline $\begin{array}{l}\text { Initial } \\
\text { diagnosis }\end{array}$ & Male & Female & Total & Percentage \\
\hline Routine & 20 & 17 & 37 & 29.6 \\
\hline $\begin{array}{l}\text { Investigation } \\
\text { on Suspicion }\end{array}$ & 9 & 18 & 27 & 21.6 \\
\hline $\begin{array}{l}\text { Chance } \\
\text { Discovery }\end{array}$ & 16 & 10 & 26 & 28.8 \\
\hline $\begin{array}{l}\text { Polyuria and } \\
\text { Polyphagia }\end{array}$ & 14 & 12 & 26 & 20.8 \\
\hline Complications & 6 & 3 & 9 & 7.2 \\
\hline
\end{tabular}

In Figure 1, number of patients who were having one comorbid condition and complication was 60 (48\%). Sixteen patients $(12.8 \%)$ had two and seven were having more than two co-morbid condition and complication. Forty two patients $(33.6 \%)$ had none of them.

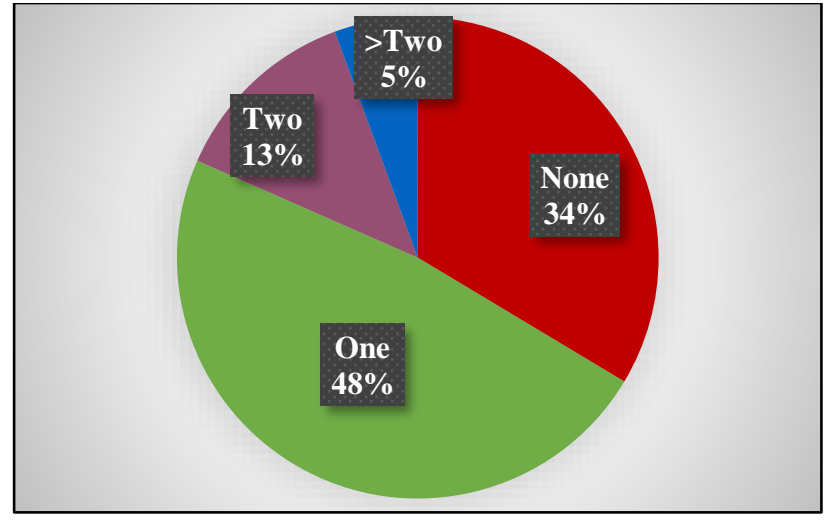

Figure 1: Percentage wise distribution of number of co-morbid conditions and complications.

In this study, prescription of 125 patients were studied. According to these, a total of 101 patients $(81.08 \%)$ were prescribed biguanides, i.e., Metformin. Sulphonylureas were given to 52 patients $(41.6 \%)$, DPP-4 Inhibitors to nine patients $(7.2 \%)$ and thiazolidinediones, particularly pioglitazone to two patients $(1.6 \%)$. Insulin was prescribed to a total of 29 patients $(23.2 \%)$. A count of three patients (6.4\%) were prescribed regular insulin, three $(2.4 \%)$ were given NPH + Regular insulin concurrently and 22 patients (17.6\%) were given 70/30 combination (Figure 2).

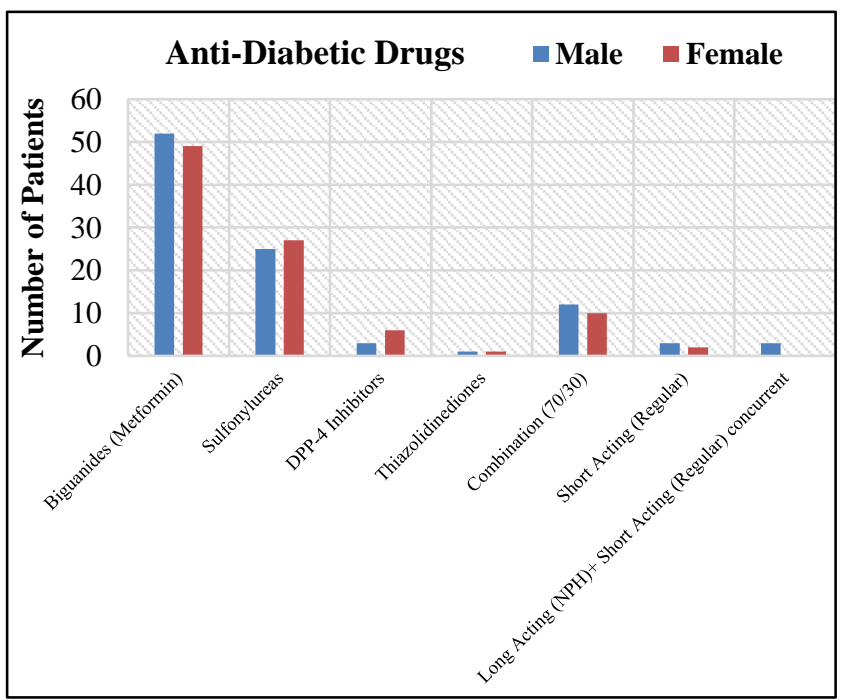

Figure 2: Distribution of patients according to antidiabetic drugs prescribed.

\section{DISCUSSION}

This study was designed to focus on the prescription pattern in diabetic patients. Drug utilization research is done to facilitate the rational use of drugs in populations, interventions to improve drug use and continuous quality improvement. Therefore, this study was designed to evaluate the prescribing pattern of anti-diabetic drugs among diabetic patients in a rural tertiary care teaching hospital providing the baseline data for future references. 
A total of 125 patients who fulfilled inclusion criteria were enrolled. Out of these, $52 \%$ were males and $48 \%$ were females showing that both the genders are almost equally predisposed to the disease. However, in study done in the South Indian population, male predominance was seen which is not in agreement with the results of our study. ${ }^{11}$ This might be due to increase in awareness of this disease and its complications in the female population with progressive time.

A count of three patients $(2.4 \%)$ were having type $1 \mathrm{DM}$ and remaining $122(97.6 \%)$ were having type 2 DM which shows much more prevalence of T2DM. Average age of the included patients suffering from diabetes was $53 \pm 12.5$ years which indicates the middle-age preponderance of this disease and matches with another study done in the past showing age group of 51-60 years having been most affected. ${ }^{12}$ In this study group, vast population $(76.8 \%)$ of the patients were from rural area since this is a study carried out in north Indian rural tertiary care hospital.

According to BMI, most of the patients, $68 \%$ fall in normal category and $22.4 \%$ were in overweight category. This is in contrary to previous studies which show BMI of most of the patients in overweight or obese category. ${ }^{12}$ This finding could be due to the active lifestyle of the rural population.

On interviewing the incidence of initial diagnosis, $29.6 \%$ patients got DM detected during routine examination and $28.8 \%$ got it discovered by chance like when they came to the doctor for some other disease and on investigations got the DM diagnosed. Most likely, this awareness and screening could be due to the regular intramural and extramural camps being conducted by our institute in the area.

Total number of drugs used per day in all the patients was 379 and the average came out to be $3.032 \pm 2.05$ (mean \pm SD). Possible reason for polypharmacy could be because of comorbid conditions and complications in diabetic patients. In a study done in Puducherry, the average number of drugs prescribed per encounter was 5.15 which is higher than ours. ${ }^{13}$ In chronic diseases like diabetes, hypertension, etc. polypharmacy is a common practice due to chances of developing co-morbid conditions and complications in later stages of diseases despite good control. This is unlike epilepsy where monotherapy is preferred.

Number of rational fixed dose combinations (FDC) given to the patients for DM were $29.76 \%$ of the total antidiabetic drugs prescribed. Metformin + Glimepiride was the maximally prescribed FDC. A study held in Maharashtra reported use of FDCs (20.25\%), with FDC of glimepiride + metformin to be the most commonly prescribed. ${ }^{14}$ Combination therapy using sulfonylurea and metformin, respectively promotes insulin secretion and reduces insulin resistance. Another study also reported
FDC of metformin and sulfonylureas to be employed the most. $^{15}$

The total of 261 drugs were prescribed from National List of Essential Medicines 2015 (NLEM) out of 379 which is $68.86 \%$ of total drugs prescribed. ${ }^{9}$ According to WHO, ideally it should be $100 \%$. Low percentage of result could be because of poor awareness among the doctors about NLEM.

Oral preparations prescribed was $86.01 \%$ whereas in other studies they were 99.035 and $95.62 \% .{ }^{16,12}$ This difference could be due to the fact that they were OPD based studies and ours included patients of both OPD and wards. The percentage of drugs given from injectable route of administration was $16.62 \%$. In another study, percentages of injectables prescribed were $20.5 \%$ of total. ${ }^{17}$ So, these comparisons prove that oral and injectable drugs prescribing was reasonable in this study group.

Amongst oral hypoglycaemic agents, $80.8 \%$ were prescribed Metformin followed by sulphonylureas $(41.6 \%)$. This is in agreement of gradual take over of Metformin as a first line agent for T2DM in a decade because sulphonylureas lead to development of secondary resistance as the disease progresses. So, either Metformin is added to the therapy or replaces it. In a study conducted in Kerala, Metformin was the most commonly prescribed drug $(68 \%)$, followed by sulfonylurea class of drugs $(49.7 \%)$ which is in agreement with our study. ${ }^{18}$ In another study held in Dehradun, it was mentioned that Metformin was most commonly used oral hypoglycaemic agent. ${ }^{16}$ In this study, amongst newer drugs DPP-4 Inhibitors were given to $7.2 \%$ patients and other newer classes like $\alpha$ glucosidase inhibitors, SGLT-2 inhibitors, etc. were not prescribed. The reason could be the high cost of these drugs as most of the population we studied belonged to rural area.

Insulin or its combinations were prescribed to $23.2 \%$ patients and $70 / 30$ combination was prescribed to 22 patients $17.6 \%$. Again 70/30 combination being the cheaper option with good glycaemic control is the reason of being first preference. No ultra short acting or Lentus were prescribed due to higher market cost.

Limitations: The sample size of the study was small due to time constraints. Pharmacoeconomics was not done because of the drug price control order during the study period causing wide fluctuations in the cost of drugs.

\section{CONCLUSION}

Many drug utilization studies have been conducted in the past in various parts of India and at global level to study various changes in prescription patterns which might be due to introduction of new drugs and techniques. They might also vary in various areas like urban, suburban or rural depending upon the financial conditions of the population. This is a continuous process to improve the 
prescribing trends. In view of this, the present study was designed to evaluate the prescribing pattern of antidiabetic drugs among diabetic patients in a rural tertiary care teaching hospital. This will be the baseline data for future references as no drug utilization study has been performed earlier here.

Funding: No funding sources

Conflict of interest: None declared

Ethical approval: The study was approved by the Institutional Ethics Committee

\section{REFERENCES}

1. Lee D, Bergman U. Studies of drug utilization. In: Strom BL, editor. Pharmacoepidemiology. $4^{\text {th }}$ Ed. New York: John Wiley and Sons; 2005:401.

2. Kennedy MSN, Masharani U. Pancreatic Hormones and Antidiabetic Drugs. In: Katzung BG, Trevor AJ, eds. Basic and Clinical Pharmacology. $13^{\text {th }}$ Ed. India, McGraw Hill; 2015:723.

3. IDF Diabetes Atlas. $7^{\text {th }}$ Ed. International Diabetes Federation; 2015. Available at: http://www.idf.org. Accessed 2017 Feb 12.

4. King H, Aubert RE, Herman WH. Global burden of diabetes, 1995 2025: Prevalence, numerical estimates, and projections. Diabetes Care. 1998;21(9):1414-31.

5. Unger J. Current Strategies for Evaluating, Monitoring, And Treating Type 2 Diabetes Mellitus. Am J Med. 2008;121(6):S3-8.

6. Krentz AJ, Bailey CJ. Oral Antidiabetic Agents: Current Role in Type 2 Diabetes Mellitus. Drugs. 2005;65(3):385-411.

7. El-Kaissi S, Sherbeeni S. Pharmacological Management of Type 2 Diabetes Mellitus: An Update. Curr Diabetes Rev. 2011;7(6):392-405.

8. Costa B, Arroyo J, Sabaté A. The economics of pharmacotherapy for Diabetes Mellitus. Pharmacoeconomics. 1997;11(2):139-58.

9. National List of Essential Medicines; 2015. Available at: cdsco.nic.in/WriteReadData/NLEM-2015/NLEM, 2015.pdf. Accessed 24 Nov 2017

10. Powers AC. Etiologic classification of Diabetes Mellitus Table 344-1. In: Longo, Fauci, Kasper, Hauser, Jameson, Loscalzo, eds. Harison's Principles of Internal Medicine $18^{\text {th }}$ Ed. Volm II. New York, Mc Graw Hill; 2011:2276.
11. Abdi SH, Churi S, Kumar RYS. Study of Drug Utilisation Pattern of antihyperglycemic agents in a South Indian tertiary care teaching hospital. Indian $\mathbf{J}$ Pharmacol. 2012;44:210-4.

12. Acharya KG, Shah KN, Solanki ND, Rana DA. Evaluation of antidiabetic prescriptions, cost and adherence to treatment guidelines: A prospective, cross-sectional study at a tertiary care teaching hospital. J Basic Clin Pharma. 2013;4:82-7.

13. Ramachandran G, Rohith V, Isabella T. Evaluation of prescribing pattern of anti-diabetic drugs using WHO prescribing indicators in a tertiary care hospital in Puducherry: A cross-sectional study. The Pharm J. 2015;4(5):76-80.

14. Agarwal AA, Jadhav PR, Deshmukh YA. Prescribing pattern and efficacy of anti-diabetic drugs in maintaining optimal glycemic levels in diabetic patients. J Basic Clin Pharma. 2014;5:79-83.

15. Santra D, Totade S. Prescribing Trends of Antidiabetic Fixed dose combinations in a rural tertiary care teaching hospital in Central India: An Observational, crosssectional study. Res. J. Pharmacology and P'dynamics. 2015;7(1):19-22.

16. Dutta S, Beg MA, Anjoom M, Varma A, Bawa S. Study of prescribing pattern in diabetes mellitus patients in a tertiary care teaching hospital at Dehradun, Uttarakhand. Int J Med Sci Public Health. 2014;3:1351-4.

17. Kumar AM, Nizar A, Shailaja K, Jayasutha J, Ramasamy C. A study on prescribing pattern and potential drug-drug interactions in type 2diabetes mellitus (inpatients) in a tertiary care teaching hospital. Der Pharmacia Lettre. 2011;3(4):13-9.

18. Alex SM, Sreelekshmi BS, Smitha S, Jiji KN, Menon AS, Devi PU. Drug Utilization Pattern of AntiDiabetic Drugs Among Diabetic Outpatients in a Tertiary Care Hospital. Asian J Pharm Clin Res. 2015;8(2):144-6.

Cite this article as: Sharma S, Chopra SC, Sharma DK, Singla J, Kapoor V. Drug utilization study in diabetic patients seeking medical treatment in a north Indian rural medical college hospital. Int J Basic Clin Pharmacol 2018;7:912-6. 